\title{
Synthetic Aperture Radar Imaging of Upper Ocean Circulation Features and Wind Fronts
}

\author{
Johnny A. Johannessen, ${ }^{1}$ Robert A. Shuchman, ${ }^{2}$ Ola M. Johannessen, ${ }^{1,3}$ Kenneth L. Davidson, ${ }^{4}$ \\ AND DAVID R. LYZENGA ${ }^{2}$
}

\begin{abstract}
Airborne $\mathrm{C}$ band synthetic aperture radar (SAR) data were collected during the Norwegian Continental Shelf Experiment (NORCSEX) carried out in March 1988. Unique signature variations in the SAR backscatter due to upper ocean circulation features and wind fronts were found. It is documented that a current jet of $0.3 \mathrm{~m} \mathrm{~s}^{-1}$ with a shear of about $0.3 \times 10^{-3} \mathrm{~s}^{-1}$ is correlated with a narrow, bright curved line in the backscatter. In comparison a rapid wind shift of $9 \mathrm{~m} \mathrm{~s}^{-1}$ resulted in a sharp transition from dark to brighter backscatter regions. The corresponding profiles of backscatter modulation across these features are expressed by a peak of about $2 \mathrm{~dB}$ in contrast to a steplike increase of 5-8 dB. This suggests that SAR image expressions of upper ocean circulation features and wind fronts can be distinguished and classified. On the basis of this classification, we attempt to quantify the dominating marine geophysical variables. This method for systematic interpretation of SAR images should be further validated with the use of airborne or satellite data such as from the first European Space Agency remote sensing satellite, ERS I.
\end{abstract}

\section{INTRODUCTION}

The first European Space Agency (ESA) remote sensing satellite (ERS 1) will be launched into polar orbit in spring 1991. ERS 1 will be equipped with an active microwave sensor package including a combined synthetic aperture radar (SAR) and scatterometer and a radar altimeter. Seasat demonstrated that the combination of such spaceborne active microwave sensors can provide measurements of surface wind, waves, and ocean surface currents (Beal et al., [1981]; see also the Seasat II collection of papers in the Journal of Geophysical Research, volume 88, number C3, 1983). In order to simulate and evaluate the ERS 1 detection capability, the pre-launch ERS 1 Norwegian Continental Shelf Experiment (NORCSEX '88) was carried out off the west coast of Norway, centered at $64^{\circ} \mathrm{N}$, in March 1988. The NORCSEX program was selected by ESA under the Announcement of Opportunity and will continue with two post-launch validation experiments in summer and fall 1991.

The sampling strategy of NORCSEX ' 88 was to measure simultaneously near-surface wind, waves, and current and their interaction by coordinated use of remote sensing and in situ data [Johannessen, this issue]. In particular, $\mathrm{C}$ band SAR measurements were acquired using the Canadian Convair-580 aircraft with the aim of investigating the feasibility of classifying and quantifying variations in SAR backscatter due to upper ocean circulation features and wind fronts.

Synthetic aperture radar imaging of the ocean surface at incidence angles from $20^{\circ}$ to $70^{\circ}$ is principally caused by resonant Bragg scattering, whereby the transmitted radar waves are scattered by short gravity waves of approximately the radar wavelength [Wright, 1978; Hasselmann et al.,

\footnotetext{
${ }^{1}$ Nansen Environmental and Remote Sensing Center, Bergen, Norway.

${ }^{2}$ Environmental Research Institute of Michigan, Ann Arbor.

${ }^{3}$ Geophysical Institute, University of Bergen, Bergen, Norway.

${ }^{4}$ Department of Oceanography, Naval Postgraduate School, Monterey, California.

Copyright 1991 by the American Geophysical Union.

Paper number 91JC00301.

0148-0227/91/91JC-00301\$05.00
}

1985]. These waves are formed in response to the wind stress. Variations of these short waves are usually induced by long gravity waves, variable wind speed and stratification in the marine atmospheric boundary layer, and variable currents associated with upper ocean circulation features such as fronts, eddies, and internal waves as well as bottom topography [Beal et al., 1981]. Expressions of these surface roughness variations have been seen in numerous spaceborne and airborne SAR images. For example, off the east coast of the United States, surface roughness patterns associated with warm water Gulf Stream rings were detected and tracked by the Seasat SAR [Lichy et al., 1981; Vesecky and Stewart, 1982]. Lichy et al. and Vesecky and Stewart also reported on SAR image manifestations of surface roughness changes reflecting mesoscale wind field patterns. Moreover, Rufenach et al. [1983] proposed to utilize the Doppler shifts induced by the radial velocities of the scatterer to obtain an estimate of the ocean surface current component perpendicular to the SAR flight track.

Recently, Barnett et al. [1989] introduced an inverse method to convert SAR data to estimates of current shear, provided that a well-defined swell as well as an ocean circulation feature exist within the illuminated area. When the method was applied to shuttle imaging radar-B (SIR-B) data gathered across the Antarctic Circumpolar Current, realistic surface current velocity fields were obtained indicating the presence of a substantial mesoscale eddy. Another attempt to apply the method in the Gulf Stream was less successful, primarily owing to lack of well-defined swell. In another recent study, Liu et al. [1989] developed a numerical model for wave refraction across a meandering current front. They showed that the main impact of a meandering current on the wave field is the formation of caustic and shadow regions in which the wave energy is significantly enhanced or reduced. The anticipated effect of the tilt modulation induced by these regions of different wave energy will in turn modulate the SAR backscatter expression. In spite of this documentation of the environmental impact on the radar backscatter, SAR images from the past have not been extensively used for studies of mesoscale upper ocean circulation or mesoscale wind field features. This is primarily 
TABLE 1. SAR and Scatterometer System Parameters During NORCSEX '88

\begin{tabular}{|c|c|c|c|c|c|}
\hline \multirow[b]{2}{*}{ Parameter } & \multicolumn{2}{|c|}{ SAR } & \multicolumn{3}{|c|}{ Scatterometer } \\
\hline & $X$ Band & C Band & $X$ Band & C Band & L Band \\
\hline Frequency, GHz & 9.35 & 5.3 & 9.50 & 5.25 & 1.50 \\
\hline Wavelength, $\mathrm{cm}$ & 3.2 & 5.6 & 3.2 & 5.6 & 20.0 \\
\hline Polarization & $V V$ & $V \boldsymbol{V}$ & $V V / V H$ & $V V / H H$ & VV/HH \\
\hline Incidence angle, deg & $45^{\circ}-85^{\circ}$ & $45^{\circ}-85^{\circ}$ & $20^{\circ}-80^{\circ}$ & $20^{\circ}-80^{\circ}$ & $20^{\circ}-80^{\circ}$ \\
\hline Ground range resolution, ${ }^{*} \mathrm{~m}$ & 15 & 15 & 0.6 & 0.7 & 2.0 \\
\hline Azimuth resolution, ${ }^{*} \mathrm{~m}$ & 7.5 & 7.5 & 0.6 & 0.7 & 2.0 \\
\hline Swath width, km & 60 & 60 & & & \\
\hline Range-to-velocity ratio, $s$ & 60 & 60 & & & \\
\hline Look direction & $\mathbf{L} / \mathbf{R}$ & L/R & starboard & starboard & starboard \\
\hline
\end{tabular}

The relationship between the radar frequency $f$ and wavelength $L$ is determined by $c=f L$, where $c$ is the speed of light. The C band SAR on ERS-1 has a radar frequency of $5.3 \mathrm{GHz}$ or radar wavelength of $5.6 \mathrm{~cm}$. In comparison, Seasat $\mathrm{L}$ band SAR operated at a frequency of $1.3 \mathrm{GHz}$ or wavelength of $23.0 \mathrm{~cm}$.

${ }^{*}$ For scatterometer at $40^{\circ}$ incidence angle.

due to lack of coordinated spaceborne and airborne SAR and in situ field measurements. An exception is the synthetic aperture radar internal wave studies in the Georgia Strait and New York Bight [Hughes and Gasparovic, 1988], where studies clearly document that surface current induced by the existence of internal waves can be quantified [Thompson et al., 1988; Kasischke et al., 1988].

The detection capabilities of SAR can be used for monitoring the temporal and spatial variability of the upper ocean circulation and wind field pattern. This is particularly likely in coastal regions, where the use of spaceborne infrared radiometers is hampered by extensive cloud cover and the determination of the wind field variability from spaceborne scatterometers is limited to a coarse spatial scales of about $50 \mathrm{~km}$.

In this paper the coordinated collection of the $\mathrm{C}$ band SAR and in situ data are described in section 2. Different airborne SAR image expressions are examined and classified according to coincident in situ measurements in section 3 . The backscatter modulation mechanisms are then discussed in section 4 , where attempts are made to quantify the geophysical variables that generate these expressions and the results are briefly compared with Seasat SAR images. A summary follows in section 5 .

\section{EXPERIMENT DESCRIPTION}

The Canadian CV-580 SAR system parameters and radar geometry during the four flights dedicated to surface feature studies are summarized in Table 1 . The SAR processing methods are described by Rufenach et al. [this issue]. The receiver dynamic range is $63.5 \mathrm{~dB}$, with a relative radiometric calibration better than $0.5 \mathrm{~dB}$ [Livingstone et al., 1987]. Each flight line was about $200 \mathrm{~km}$ long, and spacing between individual lines was about $55 \mathrm{~km}$. In wide swath, the SAR incidence angles range from $45^{\circ}$ to $85^{\circ}$, providing a ground coverage of about $60 \mathrm{~km}$ at an aircraft altitude of $7 \mathrm{~km}$ with a $7.5-\mathrm{m}$ resolution in azimuth and a $15-\mathrm{m}$ resolution in ground range. The total coverage of the two mosaics obtained on March 13 and 17 is shown in Figures $1 a$ and $1 b$. At an aircraft speed of $120 \mathrm{~m} / \mathrm{s}$ the ratio of the range distance to the illuminated target $(R)$ to the platform velocity $(V)$, usually called the $R / V$ ratio, is about $60 \mathrm{~s}$ in near range.

The real-time SAR display system was used to inform the research vessel Håkon Mosby about the location of signifi- cant features. However, the relatively poor spatial coverage obtained with the ship within synoptic time limited the number of near "real time" transects completed within 3 hours of the SAR observation (Figures $1 a$ and $1 b$ ). Shipmounted minicup anemometers and hot fill were used for atmospheric boundary layer vector wind and turbulence measurements. A shipmounted acoustic Doppler current profiler (ADCP) obtained depth profiles of the absolute current along the ship track, while the thermohaline structure and the sea surface temperature were measured along the ship track with a towed, undulating SeaSoar conductivity-temperature-depth profiler (CTD) and a ship-mounted thermistor. Four anchored wave buoys spaced about $100 \mathrm{~km}$ apart provided estimates of the directional wave spectra, the vector wind, and the air and sea surface temperature, while six subsurface Aanderaa current meter moorings provided temporal measurements of the regional ocean circulation pattern. These observations allowed characterization of the atmospheric boundary layer and the upper ocean which influence the SAR backscatter (Figure 2).

In addition a ship-mounted scatterometer on board Håkon Mosby collected multifrequency and multipolarization microwave backscatter data along the ship transects at $\mathrm{L}, \mathrm{C}$, and $X$ band at incidence angles ranging from $20^{\circ}$ to $80^{\circ}$. This enabled us to (1) obtain scatterometer measurements across SAR-detected frontal boundaries, (2) verify the SAR image expressions, (3) establish a relationship between the radar backscatter at different wavelength and the vector wind, and (4) identify possible effects on the backscatter from atmospheric boundary layer stability, sea surface temperature variations, precipitation, and mesoscale surface current patterns. The scatterometer system specifications are included in Table 1. In this paper, only results of the C band SAR and scatterometer data collection are presented.

\section{SAR IMAGE EXPRESSIONS}

$A$ variety of mesoscale and regional scale features with distinct expressions were imaged by the SAR on March 13 and 17 (Figure 3): (1) the narrow, bright, almost saturated, feature extending offshore in the upper right and the bright, curving line of increased backscatter in the upper left (Figure $3 a$ ); (2) the sudden backscatter change from dark to bright mostly aligned in azimuth direction (Figure $3 b$ ); and (3) the dark, filamentlike pattern in near range (Figure $3 c$ ). The 

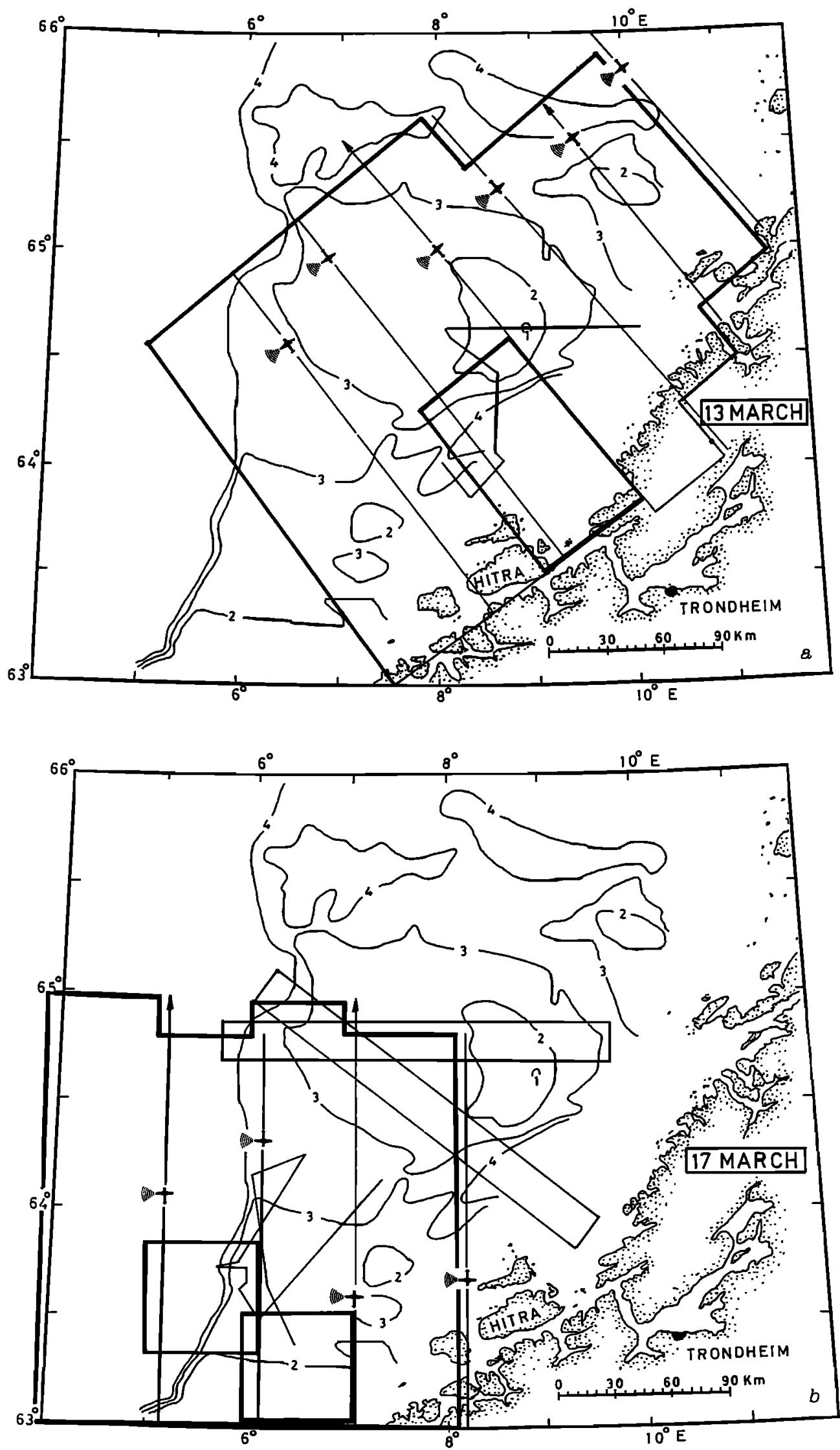

Fig. 1. Total coverage of the two mosaics, obtained on (a) March 13 and $(b)$ March 17. The SAR flight (azimuth) and look (range) directions are marked. The ship tracks obtained with $\mathrm{R} / \mathrm{V}$ Hákon Mosby during the flights are represented by the straight lines. Main bathymetry is contoured at $100-\mathrm{m}$ intervals. The shelf break is approximately located along the northward running $400-\mathrm{m}$ isobath. The rectangular boxes represents selected areas of SAR images shown in Figures $3 a, 3 b$, and $3 c$. 


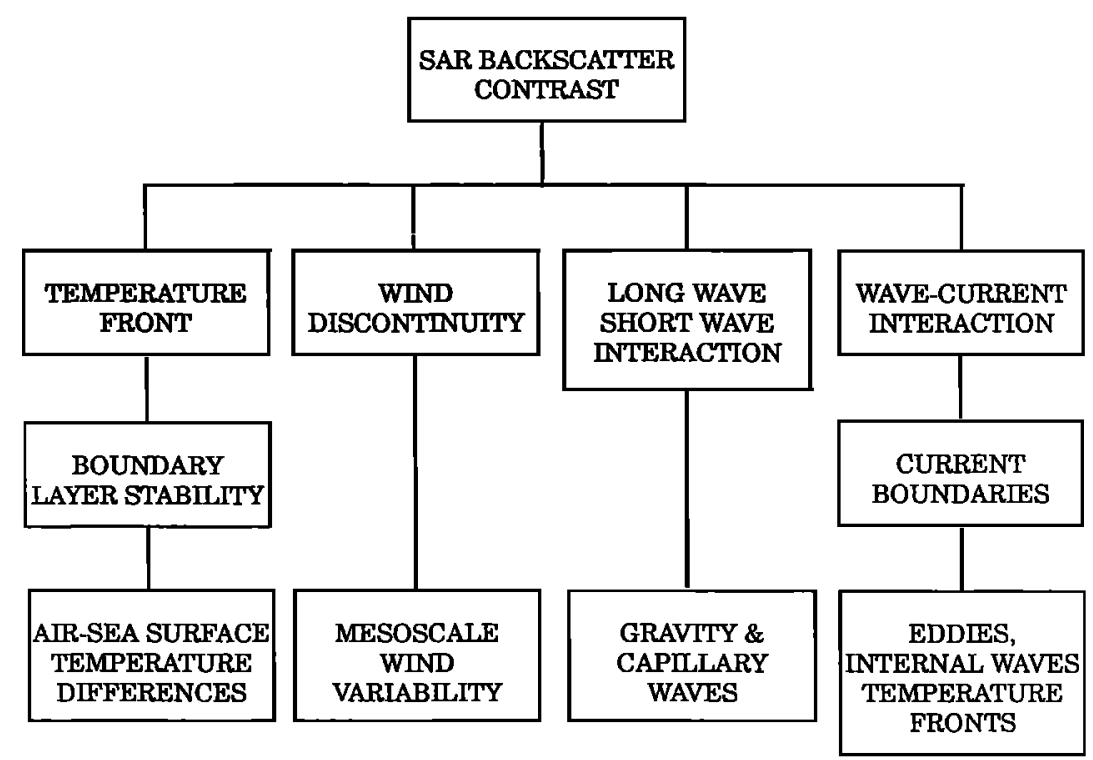

Fig. 2. Schematic illustration showing the primary geophysical quantities that modulate the normalized radar cross section measured with the SAR. (Surfactants and oil spill are not included.)

rectangular boxes in Figures $1 a$ and $1 b$ mark the positions and orientations of these images. Common for all these SAR observations was the existence of an unstable stratification in the atmospheric boundary layer with its direct impact on the near surface wind field [Keller et al., 1989]. Sufficient "sea truth" data for detailed analyses were obtained only across the current-modulated feature imaged on March 13 and the wind-modulated feature on March 17 (Figures $3 a$ and $3 b$ ).

\section{Current Feature}

The current-modulated SAR frontal expression (Figure $3 a$, left) is characterized by a bright line of increased backscatter curving slightly in the ground range direction with darker zones of less intense backscatter on both sides. An enlargement of the feature is seen in Figure 4. The corresponding profile of backscatter modulations in the direction of the ship track across the front reveals the presence of a 2- to 3-dB peak having a width of about $1 \mathrm{~km}$ (superposed in Figure 4). Note also the secondary peak of about $1.5 \mathrm{~dB}$ slightly further north.

The northward ship track (Figure $1 a$ ) was completed 3 hours after the SAR image was taken. A pronounced current jet and current shear associated with an upper ocean circulation feature are located in the vicinity of the apparent SAR signature toward the end of the track (Figure $5 a$ ). The ADCP current vectors at $15-\mathrm{m}$ depth indicate an average jet speed of $0.3 \mathrm{~m} \mathrm{~s}^{-1}$ (maximum speed, $0.37 \mathrm{~m} \mathrm{~s}^{-1}$ ) oriented parallel to the imaged front. The horizontal current vectors represent averages over $300-400 \mathrm{~m}$, while the spatial resolution in the SAR backscatter profile is about $30 \mathrm{~m}$. Highfrequency changes in the current may therefore be smoothed by the ADCP spatial sampling interval.

The evolution of the current vectors at deeper levels down to $50 \mathrm{~m}$ shows little vertical current shear and rotation (Figure $5 a$ ). The vertical temperature stratification observed in the upper layer with the towed, undulating SeaSoar is also weak in correspondence with lack of vertical shear (Figure $5 b$ ). Combined with the existence of moderate wind condi- tions (Figure 6), this indicates that the current pattern at 15 $m$ is a good representation of the surface current field. Perpendicular to the front, the maximum current shear is estimated to be about $0.3 \times 10^{-3} \mathrm{~s}^{-1}$. The convergence is at least an order of magnitude smaller. No direct surface current measurements collected with the CODAR array in the region were available on this day [NORCSEX' 88 Group, 1989].

Twenty minutes $(4 \mathrm{~km})$ worth of ADCP data are missing to the south of the jet, making it difficult to get a complete picture of the lateral velocity structure. However, examination of the along-track temperature structure in the upper 150 $\mathrm{m}$ (Figure $5 b$ ) suggests that the jet can represent the northern sector of a cyclonic eddy. The southern sector is then evidently represented by the eastward flow of about $0.20 \mathrm{~m}$ $\mathrm{s}^{-1}$ observed prior to the data gap.

In general, the wind speed observed along the ship track with cup anemometers decreased gradually from $6 \mathrm{~m} \mathrm{~s}^{-1}$ to $4 \mathrm{~m} \mathrm{~s}^{-1}$ (relative accuracy of $0.5 \mathrm{~m} \mathrm{~s}^{-1}$ ) with a steady direction toward the east crossing the southwestward directed jet at an angle of about $45^{\circ}$ (Figure 6). The stratification remained unstable with $T_{\text {arr }}-T_{\text {sea }}$ between $-2^{\circ}$ and $-5^{\circ} \mathrm{C}$, with a tendency to grow more unstable toward north, apparently in correspondence with the gradual increase in sea surface temperature (Figure 6). The radar scattering cross section as measured by the ship-mounted scatterometer increases gently at first in contrast to the gradual decrease in wind speed. Subsequently, two peaks of about $3 \mathrm{~dB}$ and $2 \mathrm{~dB}$ are seen. These peaks are located in vicinity of the current jet. No correlation to the wind speed or stability fluctuations are clearly evident.

Temporal variations of the thermohaline and current structure (considered to be in geostrophic balance) in the upper ocean in the 3-hour period after the SAR observations can be ignored. Moreover, since the eddy advection speed in the region is reported to be about $6 \mathrm{~km} \mathrm{~d}^{-1}$ [Haugan et al., this issue], spatial variations within 3 hours can also be ignored. In contrast, temporal and spatial fluctuations of the wind field of a few meters per second under unstable 

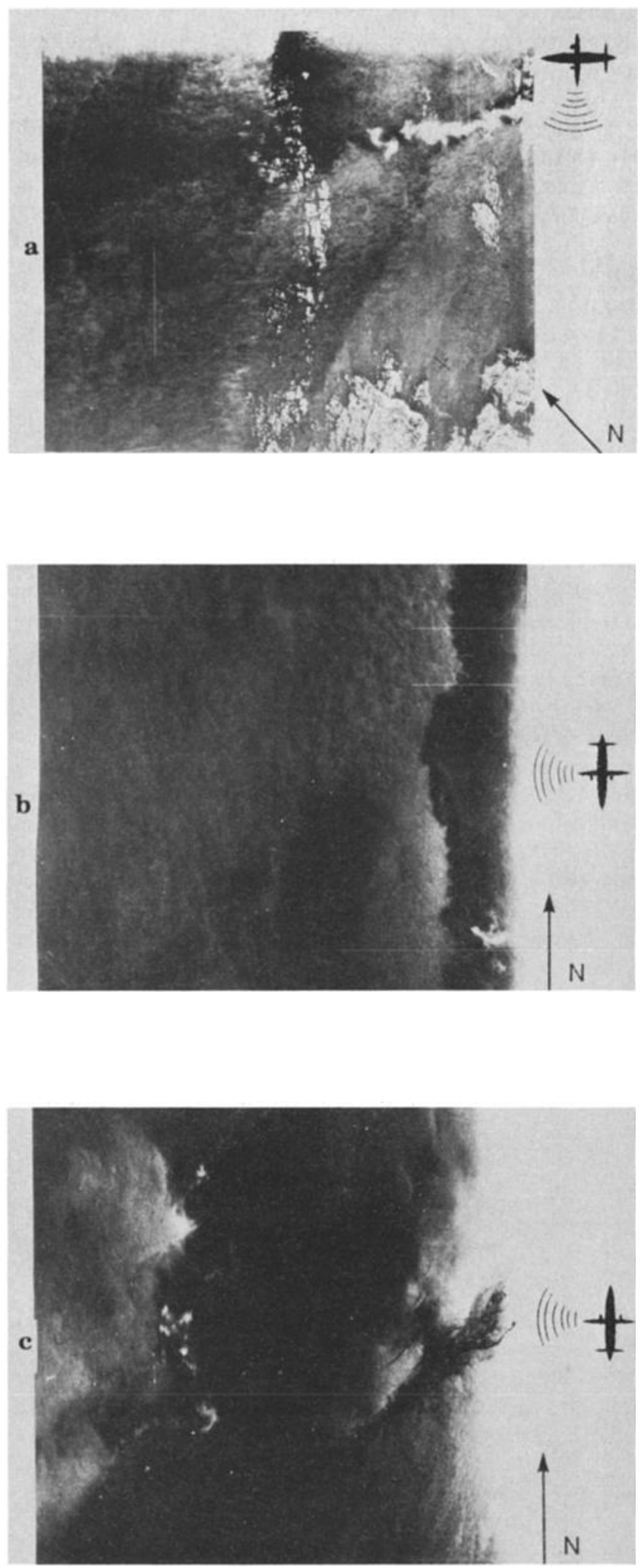

Fig. 3. Examples of three different SAR image expressions obtained during NORCSEX '88: (a) near-saturated backscatter (top right) and bright, curving line of increased backscatter (top left) obtained on March 13; $(b)$ rapid transitions from low- to highbackscatter regions oriented perpendicular to SAR look (range) direction obtained on March 17; and (c) filaments of low backscatter (right) obtained on March 17. Note also the scattered patches of near-saturated backscatter in Figures $3 b$ and $3 c$. SAR flight and look directions are marked in near-range positions of the images. Arrows points north. The wide swath width is approximately $60 \mathrm{~km}$.

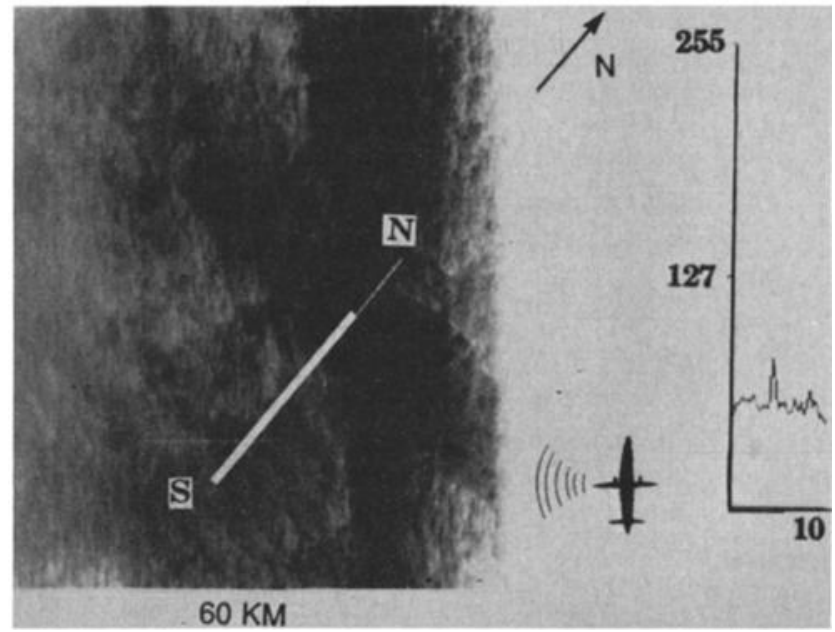

Fig. 4. Enlargement of the left side of the SAR image (Figure 3a) obtained on March 13 at 1030 UT. The image is about $60 \mathrm{~km}$ in range direction. Flight and look directions are indicated. Arrow points north. The ship transected northward from $S$ to $N$. The peak in the backscatter profile of about $2 \mathrm{~dB}$ seen to the right is obtained along the $10 \mathrm{~km}$ thin scan line superposed across the frontal feature. The backscatter along the vertical axis is given in amplitude. The SAR data are normalized by transforming the image amplitude values along the vertical axis into radar cross-section values $\left(\sigma^{0}\right.$, in decibels).

stratification in the atmospheric boundary layer are expected. In Figure 4 it is clearly seen that the radar cross section is more intensive away from the narrow bright line in the far range sector of the image. This suggests that the wind speed in vicinity of the frontal boundary was considerable lower than $6 \mathrm{~m} \mathrm{~s}^{-1}$ reported at the ship position in the far range sector at the time of overpass. Consequently, only the ship observations of the temperature and current structure are considered to be representative for the conditions at the time the feature was imaged by the SAR. The short-wave modulation induced by the presence of the upper ocean current jet is therefore proposed to contribute to the peak in the backscatter signal. This is discussed further in section 4.

The other features expressed in Figures $3 a$ and $3 c$ are also assumed to manifest upper ocean circulation features. In Figure $3 a$ (right) the near-saturated backscatter may reflect a zone of strong current convergence and divergence extending offshore. However, we offer no explanation for the generation of this feature. In contrast, we assume that the dark filament like expression in Figure $3 c$ is located in vicinity of an ocean front, where the convective motion of the water masses form upwelling zones accompanied by surface slicks that dampen the Bragg-scattering waves. The temperature field provided by the satellite IR image obtained a day earlier as well as a numerical circulation model document that a frontal boundary is located in this region [Haugan et al., this issue]. When surfactants (surface slicks) are found along ocean circulation features, the SAR backscatter signature is reversed, providing a drop in backscatter across the frontal structure in contrast to the peak discussed above. More studies are needed to understand the formation and behavior of naturally caused surface slicks. In Figure $3 c$ a few scattered areas of bright backscatter are also observed. We lack data to interpret these features. 


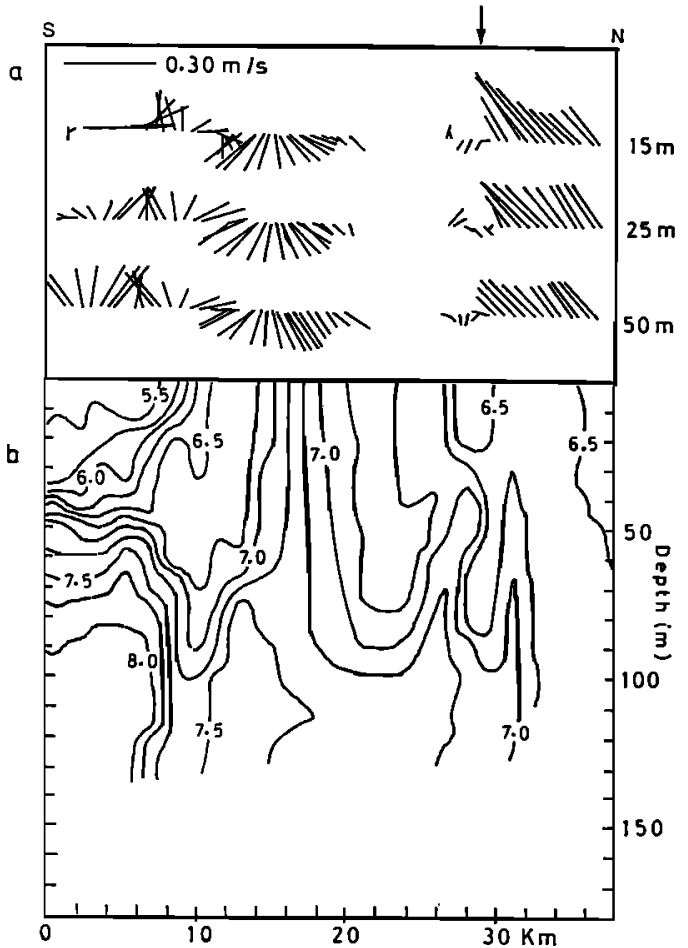

Fig. 5. Velocity and thermal stratification along the northward ship track from $S$ to $N$ (Figure 4) crossing the SAR-detected frontal boundary. (a) ADCP current vectors at a depths of 15,25 , and $50 \mathrm{~m}$. (b) Thermal stratification in the upper $150 \mathrm{~m}$ contoured very $0.25^{\circ} \mathrm{C}$. The ADCP measures the acoustic backscatter from the water and the bottom down to about $500 \mathrm{~m}$. The absolute current is determined from the Doppler shift. The vertical resolution is selected at $8 \mathrm{~m}$. The sampling interval is selected at $150 \mathrm{~s}$, equivalent to a horizontal resolution of about $400 \mathrm{~m}$. The SeaSoar in general collects no data above $5 \mathrm{~m}$. The arrow at the top mark the position of the SARimaged front relative to the ship track. Distance along track is given in kilometers from $\mathrm{S}$ to $\mathrm{N}$.

\section{Wind Front}

The SAR image expression obtained on March 17 (Figure $3 b$ ) is characterized by a rapid change from low to high SAR backscatter mostly oriented in azimuth direction as seen in the enlargement in Figure 7. In turn, a steplike profile with an 6- to 8-dB increase over about $1 \mathrm{~km}$ (superposed in Figure 7) is encountered across the front in contrast to the current modulated peak in the backscatter profile (Figure 4).

The spatial wind speed $(U)$ variations observed along the ship track (Figure $1 b$ ) across this front within less than 20 min show a sudden increase from about $3 \mathrm{~m} \mathrm{~s}^{-1}$ to $12 \mathrm{~m} \mathrm{~s}^{-1}$ (Figure 8). In turn, the friction velocity, which primarily determines the surface roughness, increase from 0.1 to $0.5 \mathrm{~m}$ $\mathrm{s}^{-1}$. Simultaneously, the wind direction shifted from westerly to northwesterly. The air temperature increased by almost $2^{\circ} \mathrm{C}$ across the wind front, suggesting the presence of a warm front. Since the sea surface temperature remained unchanged across the wind front, the stratification in the atmospheric boundary layer therefore approached nearneutral conditions $\left(-2^{\circ}\right.$ to $\left.+2^{\circ}\right)$, before it gradually returned to the unstable conditions, with $T_{\text {arr }}-T_{\text {sea }}$ about $-4^{\circ} \mathrm{C}$, experienced prior to the frontal crossing (Figure 8). No precipitation was encountered during the frontal crossing. The frontal crossing furthermore led to a steplike scatterometer backscatter increase of about 5-7 dB (Figure 8). However, because of data gaps on the low wind side of the front the backscatter increase did not display the steplike structure that was observed with the SAR.

About 10-15 km west of the wind front the sea surface temperature had increased by almost $3^{\circ} \mathrm{C}$. Associated with this sea surface temperature increase from the coastal water into Atlantic water, the ADCP current vectors display a weak current shear and convergence both less than $O\left(10^{-4}\right.$ $\mathrm{s}^{-1}$ ) (Figure $9 a$ ). Moreover, the stratification in the upper ocean not surprisingly documents the existence of the oceanic front (Figure $9 b$ ).

The position and orientation of this front is controlled by the shelf break as discussed by Haugan et al. [this issue]. The SAR image shows no distinct modulation pattern associated with this oceanic front. Although the positions of the two fronts were closer at the time of the SAR observations, the wind front had passed the ocean front, and we therefore expect the wind which exceeds $10 \mathrm{~m} \mathrm{~s}^{-1}$ to mask any modulation induced by this relatively weak ocean front. Lichy et al. [1981], using Seasat L band SAR data, were able to track signatures of warm water rings in the Gulf Stream up to wind speeds of about $7 \mathrm{~m} \mathrm{~s}^{-1}$, while at higher winds up to $13 \mathrm{~m} \mathrm{~s}^{-1}$ the signature became masked.

In the regions of high wind the SAR image shows patterns of wind streaks aligned in the wind direction with an angle of about $20^{\circ}$ relative to the frontal boundary. The streaks may be associated with atmospheric boundary layer convective roll circulation, which tends to be more active at unstable stratification [Gerling, 1986]. It has also been suggested that it is associated with the systematic along-wind-streak pattern induced by wind-driven Langmuir circulation in the upper mixed layer of the ocean. The SAR-derived wind direction in the high-wind-speed region is in agreement with the weather

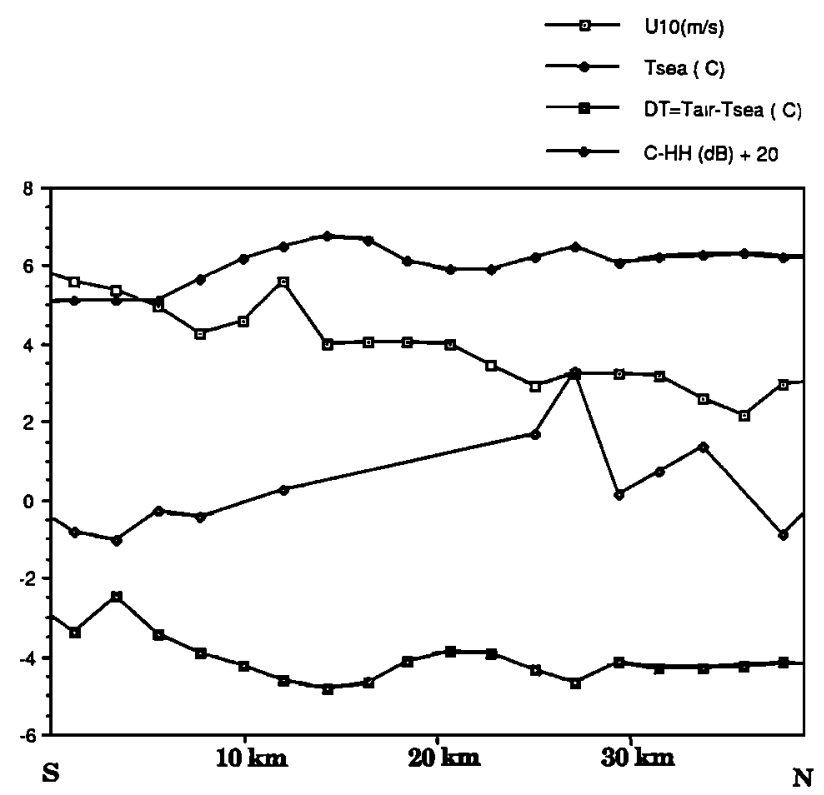

Fig. 6. Coincidental measurements of scatterometer radar scattering coefficient $\left(\sigma^{0}\right)$ at $5.3-\mathrm{GHz}$ horizontal polarization, wind speed, sea surface temperature and boundary layer stratification ( $T_{\text {air }}-T_{\text {sea }}$ ) obtained along the northward ship transect from $\mathrm{S}$ to $\mathrm{N}$ (Figure 4). Data points are averaged to $10 \mathrm{~min}$. Where no scatterometer data are present linear interpolation have been used. The vertical axis are in meters per second and degrees Celsius. The scatterometer $\sigma^{0}$ values (decibels) are only relative. Distance along track is given in kilometers from $\mathrm{S}$ to $\mathrm{N}$. 


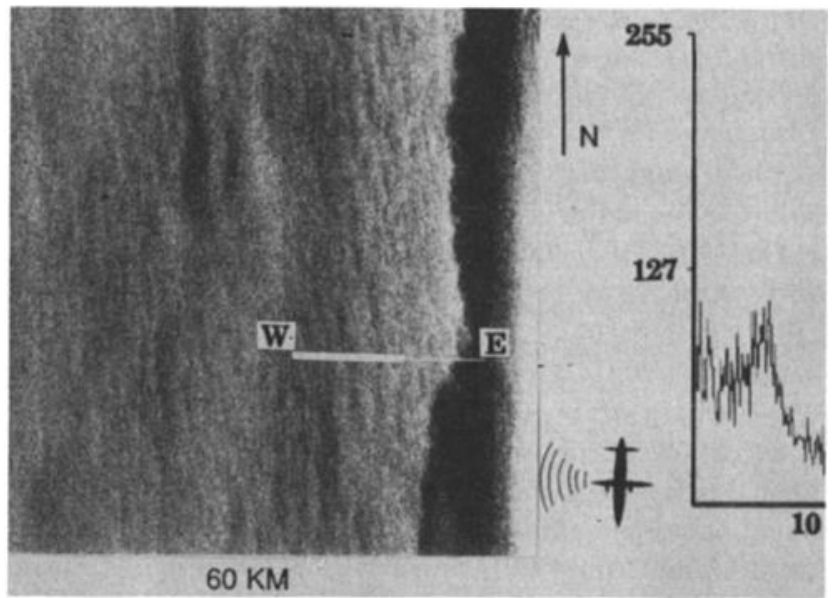

Fig. 7. Enlargement of the SAR image (Figure $3 b$ ) obtained on March 17 at 1030 UT. The image width is about $60 \mathrm{~km}$ in range direction. Flight and look directions are indicated. Arrow points to north. The ship transected from $\mathrm{E}$ to $\mathrm{W}$. The steplike backscatter profile of about 5-8 dB shown to the right is obtained along the 10-km superposed thin scan line centered across the frontal feature. The SAR data are normalized by transforming the image amplitude values along the vertical axis into radar cross-section values $\left(\sigma^{0}\right.$ decibels).

map. On the other hand, the rapid wind shift expressed in the SAR image is not displayed in the weather map, since the map in general lacks high spatial resolution.

Expressions of steplike frontal boundaries were found in several SAR images having frontal orientations parallel or orthogonal to the SAR look direction [Mognard et al., this issue]. This documents that the SAR is capable of detecting rapid wind shifts associated with atmospheric frontal bound-

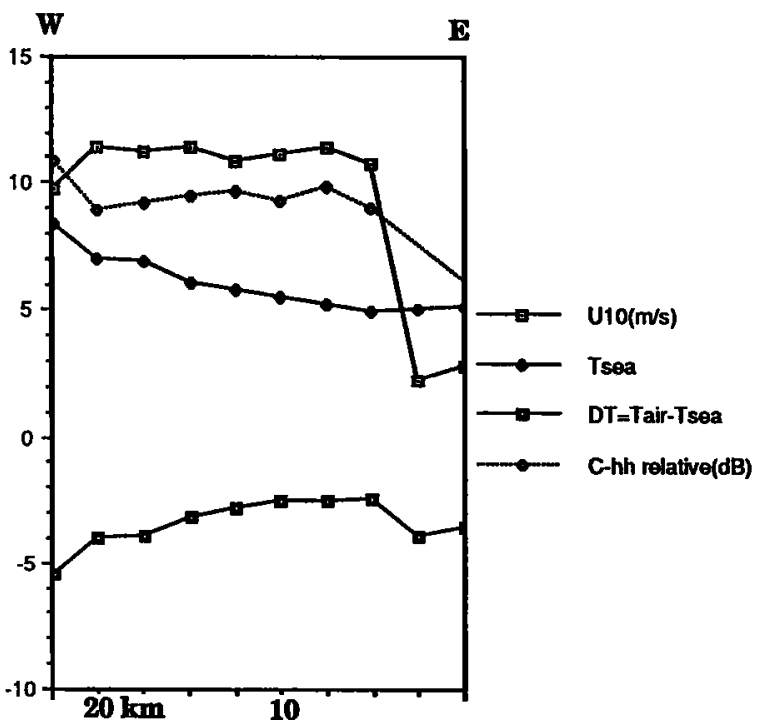

Fig. 8. Coincidental measurements of wind speed, scatterometer radar scattering coefficient at $5.3-\mathrm{GHz}$ horizontal polarization, sea surface temperature, and boundary layer stratification $\left(T_{\text {air- }}\right.$ $T_{\text {sea }}$ ) obtained along the westward ship transect from $\mathrm{E}$ to $\mathrm{W}$ (Figure 7) across the wind-modulated frontal boundary. The data points are averaged to $10 \mathrm{~min}$. The vertical axis is in meters per second and degrees Celsius. The scatterometer $\sigma^{0}$ values (decibels) are only relative. Distance along track is given in kilometers from $\mathbf{E}$ to $\mathbf{W}$.

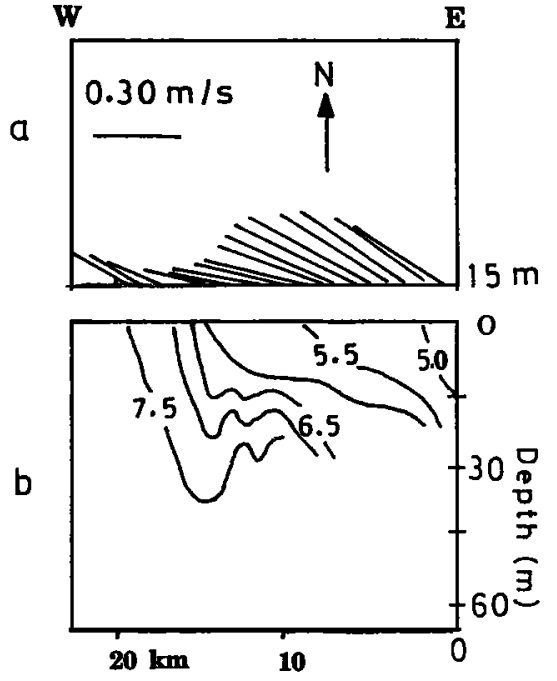

Fig. 9. Velocity and thermal stratification along the westward ship track from $\mathrm{E}$ to $\mathrm{W}$ (Figure 7). (a) ADCP current vectors at a depth of $15 \mathrm{~m}$. (b) Thermal structure in the upper $60 \mathrm{~m}$ contoured every $0.5^{\circ} \mathrm{C}$. Distance along track is given in kilometers from $\mathrm{E}$ to W.

aries independent of the orientation relative to the look direction.

\section{Discussion}

Comparison of these SAR image expressions demonstrates that upper ocean circulation features and atmospheric wind fronts provide characteristic and distinguishable SAR backscatter modulations. The SAR images can therefore be classified according to dominating modulation mechanisms. In turn, one can attempt to quantify the geophysical variables that are responsible.

\section{Current Feature}

In the preceding section we proposed that the short-wave modulation induced by the presence of the current jet was considered to contribute to the SAR image expression. Two effects are considered: (1) interaction of short gravity waves and currents, and (2) stress enhancement across the jet induced by an increment in the wind velocity relative to the opposing surface current.

In the absence of current gradients, the short-wave spectral density is determined by a balance between the wind input and dissipation rate. Deviation from this equilibrium state can be induced by wave-current interaction in the presence of either converging or shearing currents. A characteristic time scale for the reestablishment of this equilibrium state after a disturbance is given by the inverse of the wave growth rate $\beta$. If this relaxation time is smaller than the time required for a wave to propagate through the current pattern, the deviation from equilibrium caused by the current is given by

$$
f=\frac{N-N_{0}}{N_{0}}=\frac{1}{\beta}\left(k_{x} \frac{d u}{d x}+k_{y} \frac{d v}{d x}\right) \frac{1}{N_{0}} \frac{\partial N_{0}}{\partial K_{x}}
$$

where $N_{0}$ is the equilibrium action spectral density, $k_{x}$ and $k_{y}$ are the wave number components in the direction of the current gradient and in the orthogonal direction, respec- 
tively, and $u$ and $v$ are the corresponding components of the surface current (D. R. Lyzenga, Interaction of short surface waves with ocean fronts, submitted to Journal of Geophysical Research, 1990).

According to Plant [1982], the growth rate can be expressed as

$$
\beta=0.04\left(\frac{u^{*}}{c}\right)^{2} \omega
$$

where $u^{*}$ is the friction velocity, $c$ is the phase speed, and $\omega$ is the wave frequency. The friction velocity $u^{*}$ is related to the wind speed $U_{w}$ through the relationship $u^{*}=C_{d}^{0.5} U_{w}$ (with a drag coefficient $C_{d}=1.3 \times 10^{-3}$ ), and the wave phase speed is given by $c=(g / k)^{0.5}=\omega / k$ for gravity waves with wavelength $k$ and wave frequency $\omega$. Thus the growth/relaxation rate increases as the square of the wind speed and decreases with increasing wavelength. At the $\mathrm{C}$ band wavelength of $0.056 \mathrm{~m}$, the growth rate for the Bragg waves is $\beta \cong 0.18 \mathrm{~s}^{-1}$ for a wind speed of $3 \mathrm{~m} \mathrm{~s}^{-1}$ and $\beta \cong$ $0.5 \mathrm{~s}^{-1}$ for a wind speed of $5 \mathrm{~m} \mathrm{~s}^{-1}$. In addition, since the equilibrium action spectral density $N_{0}$ is proportional to $k^{-4.5}\left[\right.$ Phillips, 1981] the term $\left(k_{x} / N_{0}\right)\left(\partial N_{0} / \partial K_{x}\right) \approx-4.5$. When these values are inserted into (1), we obtain a spectral perturbation $f \approx(0.3-0.8) \times 10^{-2}$ when the measured current shear $d v / d x$ of $0.3 \times 10^{-3} \mathrm{~s}^{-1}$ is assumed. Hence the relaxation model does not appear to be capable of explaining the observed strength of the backscatter front (Figure 4) assuming a Bragg scattering model. We are led therefore to conclude that either (1) the observed changes in backscatter are due to longer waves, which undergo larger perturbations because of their smaller relaxation rates, (2) the actual current gradient is larger than that inferred from the ADCP measurements, or (3) there are flaws in the relaxation model used, and/or there are additional mechanisms not incorporated in this model.

Changes in backscatter can be caused by perturbations of longer (meter-scale) waves through the tilt effect, according to a two-scale scattering model [Lyzenga and Bennett, 1988], or possibly through other effects such as wave breaking which are not well understood. Much larger perturbations are predicted at wavelengths of the order of $1 \mathrm{~m}$, because the relaxation rates for such waves are more than an order of magnitude smaller than for the $\mathrm{C}$ band Bragg waves. Nevertheless, detailed calculations suggest that even if the long-wave effects are included through the two-scale model, the current gradients must still be increased by about an order of magnitude in order to explain the observed backscatter variations.

We hypothesize therefore that the largest SAR signatures are due to current variations on a scale of some tens of meters to a hundred meters rather than hundreds of meters. If this hypothesis is correct, an adequate characterization of these currents would require a fine-scale sampling procedure which could probably be obtained by shipboard ADCP measurements, provided that current boundaries localized in SAR images are made available in near-real time.

Additional contribution to the backscatter change and corresponding image expression can be the stress enhancement induced by an increment in the wind velocity relative to the surface current across the jet. This effect is similar to the enhancement of the drag coefficient and stress that are observed across sea surface temperature fronts $[F u$ and
Holt, 1982]. Especially at low winds the presence of a current jet can introduce a change in the surface stress dependent on the relative wind-current direction. In this particular case the wind blows against the jet at an angle of about $45^{\circ}$. In turn the stress and hence the surface roughness will increase in the jet region. The corresponding increase in backscatter intensity can be approximated by the simple expression

$$
\sigma=\sigma^{*}(\Phi, d T, S L, \cdots)\left(\mathbf{u}_{w}-\mathbf{u}_{c}\right)^{15}
$$

where $\sigma$ is the total radar backscatter intensity, and $\sigma^{*}$ is the backscatter contribution determined by radar and environmental parameters such as radar look direction versus wind direction $(\Phi)$, stability $(d T)$, wave slope $(S L)$, etc. The contribution from the near surface wind $\left(\mathbf{u}_{w}\right)$ and current $\left(u_{c}\right)$ is included in the second parentheses. A wind speed exponent of 1.5 is used in accordance with Keller et al. [1989]. At a wind speed of $2 \mathrm{~m} \mathrm{~s}^{-1}$ opposing a current jet of $0.30 \mathrm{~m} \mathrm{~s}^{-1}$ at an angle of $45^{\circ}$, the increase in $\sigma$ is about $15 \%$ relative to the backscatter value in the absence of the current jet. This in turn is sufficient to provide about a $0.65-\mathrm{dB}$ increase in the backscatter.

The SAR image expression shows no clear evidence of the current feature in the southern sector of the eddy. However, in this sector the wind, short-wave propagation, and current flow direction are aligned in a different geometry with respect to the radar look direction. This suggests that only selected sectors of a uniform, spiraling eddy may be clearly captured in the SAR image. A manifestation of this is seen in the Seasat SAR image obtained from the experimental region during calm offshore winds of $2-4 \mathrm{~m} \mathrm{~s}^{-1}$ (Figure 10). The image shows the narrow, bright curving backscatter signature (about $2 \mathrm{~dB}$ ) corresponding to a mesoscale cyclonic orbital eddy feature with a diameter of about $20 \mathrm{~km}$. In the northwestern and southeastern sector of the eddy the narrow, bright backscatter are clearly detected. On the other hand, the sectors of the eddy where the structure loops anticlockwise in southeastward and northwestward (ground range) directions are not as well imaged. Similarly, Seasat images of rings in the Gulf Stream are also characterized by a series of straight and curved bright filamentary structures less than $1 \mathrm{~km}$ wide and between 25 and $150 \mathrm{~km}$ long [Vesecky and Stewart, 1982].

\section{Wind Front}

According to its definition the geostrophic wind is parallel to the isobars, while the separation distance of isobars is inversely related to the magnitude of the wind speed. Changes in wind speed and direction are therefore expected across atmospheric fronts. This is schematically illustrated below [after Eliassen and Pedersen, 1977] for several cold and warm front cases associated with cyclonic low pressure systems (Figure 11a). As documented from the weather map, the frontal expression imaged by the SAR is connected to an atmospheric low centered to the north of the front. From dynamic considerations it follows that the pressure must be continuous through the front; otherwise there would be an infinite pressure gradient. This is known as the dynamic boundary condition for fronts. However, since the pressure gradient normal to the front is discontinuous, the isobars crossing the front must have a break point. Thus the isobars and subsequently the wind direction across the front 


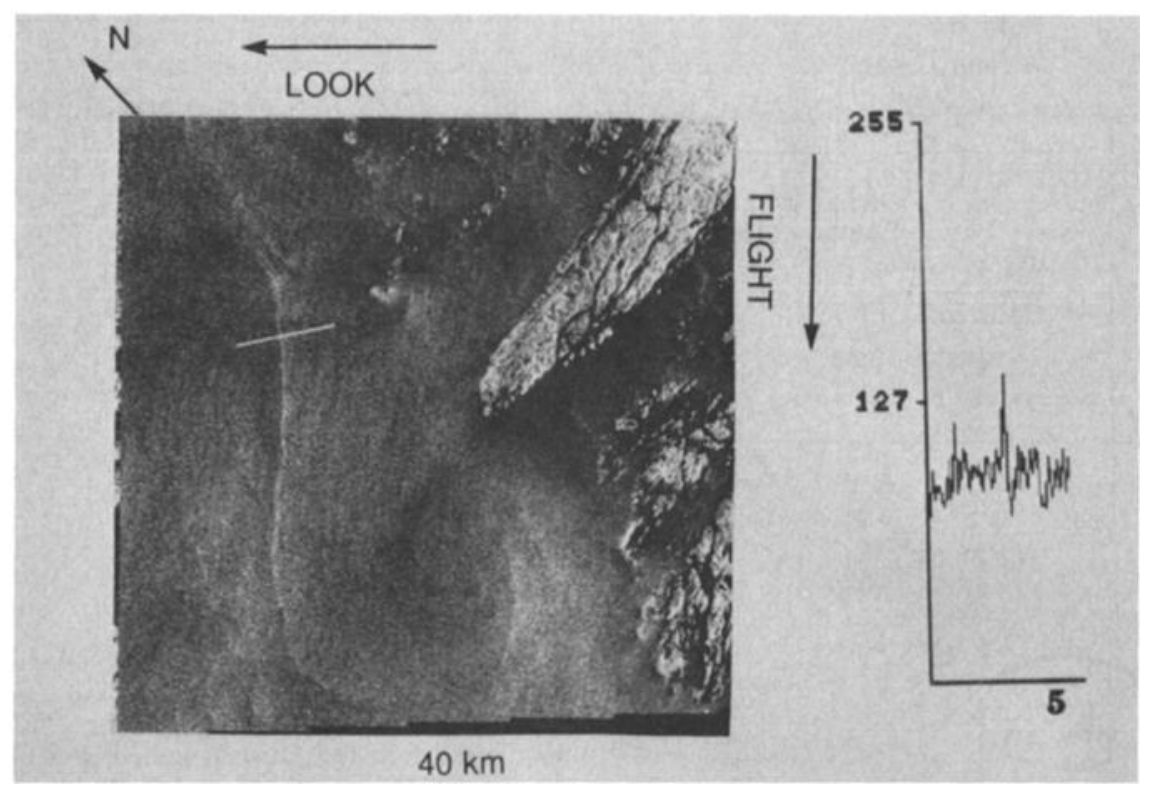

Fig. 10. Seasat SAR image of mesoscale current feature along the coast of Norway. Scale, flight, look direction, and north are indicated. The backscatter profile shown to the right is obtained along the 5-km scan line superposed perpendicular to the boundary. The backscatter values along the vertical axis are in amplitude. Conversion to decibels is obtained using $10 \log _{10} A$.

turn from northwesterly in the high-wind region to westerly in order to satisfy the wind change across the front (Figure $11 b)$.

Moreover, the kinematic boundary condition requires that the wind components normal to the frontal surface must be the same in both air masses. Departure from this is due to turbulence and mixing of the two air masses at the frontal boundary. The use of the normal part of the horizontal component of the wind in the cold air mass usually gives good estimate of the frontal movement. On the other hand, the use of the normal part of the horizontal component of the wind in the warm air tends to overestimate the frontal speed by $20-40 \%$ [Haltiner and Martin, 1957]. This is due to the fact that the wind in the warm air has a tendency to glide upward over the frontal surface, which does not necessarily cause a horizontal displacement of the front.

Provided the kinematic boundary condition is corrected for the assumption mentioned above the ratio of the high wind $\left(u_{1}\right)$ to low wind $\left(u_{2}\right)$ across the wind front (Figure 7) can be expressed as

$$
\frac{u_{1}}{u_{2}}=d \frac{\sin \beta_{2}}{\sin \beta_{1}}
$$

where $d$ ranges from 1.25 to 1.67 because $u_{1}$ is reduced to 80 or $60 \%$, and $\beta_{1}$ and $\beta_{2}$ are the horizontal wind directions relative to the front. Streak patterns which indicate wind directions were only recognized in the high-wind region (Figure 7) with a relative wind direction to the front of about $20^{\circ}$, in good agreement with the direct wind observations. No ratio could therefore be directly estimated from this SAR image. However, the wind speed ratio can also be independently derived by use of the radar backscatter equation. As long as the backscatter intensity is unsaturated, the relationship of the vector wind to the normalized radar cross section $\sigma^{0}$ [Jones and Schroeder 1978; Stewart, 1985], is given by

$$
\begin{aligned}
\sigma_{1,2}^{0}(\mathrm{~dB})= & a 10 \log _{10} u_{1,2} \\
& \cdot \frac{1+b \cos \Phi_{1,2}+c \cos 2 \Phi_{1,2}}{1+b+c}+\text { const }
\end{aligned}
$$

where subscripts 1 and 2 refer to high- and low-wind regions of the front and $\Phi$ is the angle from range direction (upwind) to the wind direction (Figure $11 b$ ). This equation is rearranged in order to obtain an expression for the wind speed ratio

$$
\frac{u_{1}}{u_{2}}=10^{\Delta \sigma / a 10} \frac{1+b \cos \Phi_{2}+c \cos 2 \Phi_{2}}{1+b \cos \Phi_{1}+c \cos 2 \Phi_{1}}
$$

In this case the two coefficients $b$ and $c$ are assumed wind speed independent. The coefficients $a, b$, and $c$ are determined from the scatterometer data (at a mean incidence angle of $40^{\circ}$ ) as $1.5,0.065$, and 0.45 . The wind speed exponent $a=1.5$ is in agreement with Keller et al. [1989], while Feindt et al. [1986] obtain average $b$ and $c$ values of 0.12 and 0.50 at incidence angle of $45^{\circ}$, and with corresponding standard deviations of 0.08 and 0.12 . Consequently, the scatterometer-derived values reported here fall within their range of observed values. The SAR image (Figure 7), on the other hand, locates the front at a mean incidence angle of $70^{\circ}$ in this particular region of the image. However, in the northern part of the mosaic obtained on March 17 the front crosses the image in near range. This suggests that the coefficients determined at $45^{\circ}$ incidence angle can be used in the equations. The different angles used in (4) and (6) are related, since the frontal orientation relative to azimuth look direction can be expressed as $\Omega=\beta_{1,2}+\Phi_{1,2}-90^{\circ}$, where subscripts refer to the high- and low-wind-speed regions (Figure $11 b$ ).

When the two expressions for the wind speed ratio are 

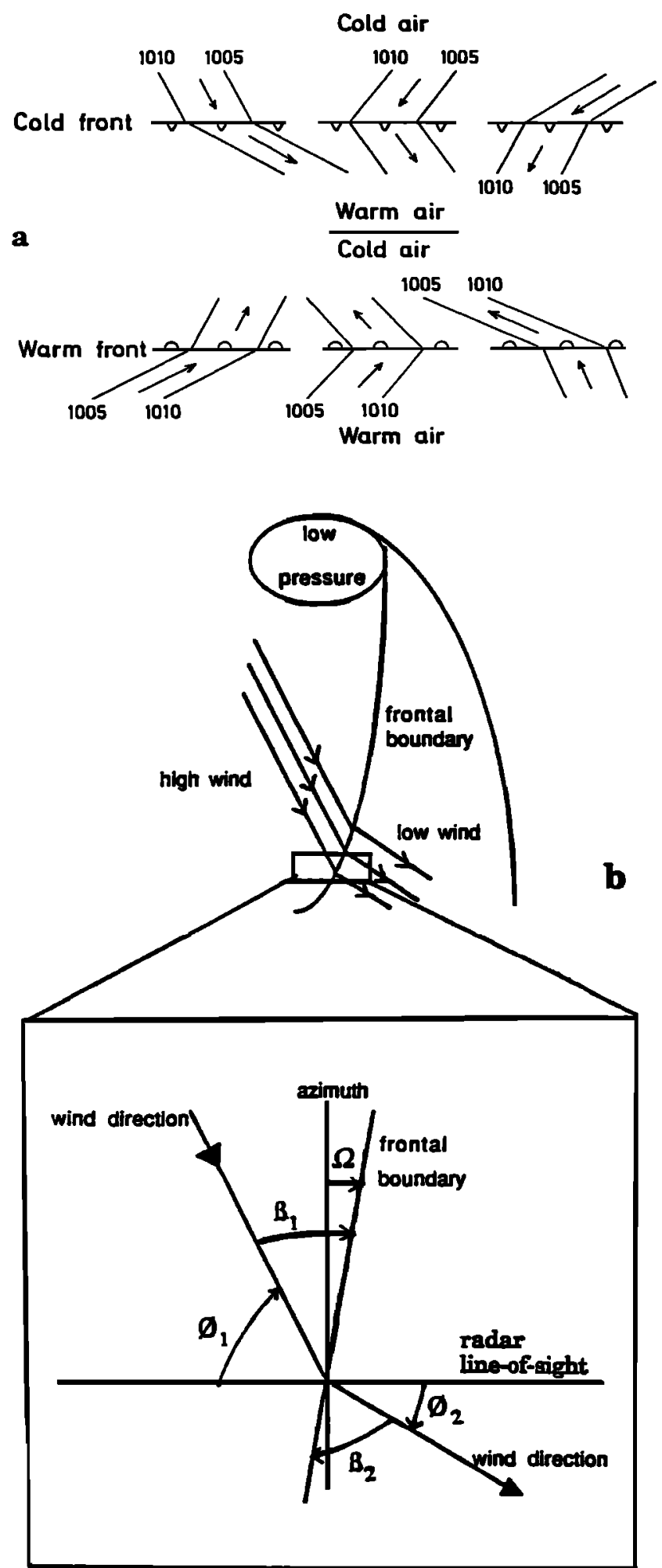

Fig. 11. (a) Schematic illustration of wind direction change relative to different types of warm and cold fronts; and $(b)$ interpretation of the wind direction change across the SAR imaged steplike (wind) front. $\Phi_{1}>\Phi_{2}$ because the radar look direction remains unchanged while the wind direction turns more antiparallel to the look direction in the low-wind-speed region.

plotted versus variable angle $\beta_{2}$, matching solutions can be found. The results are shown in Figure 12. Three curves based on (6) are plotted for the combinations of coefficients $b, c$ of $(0.065,0.45),(0.20,0.30)$, and $(0.12,0.30)$, using

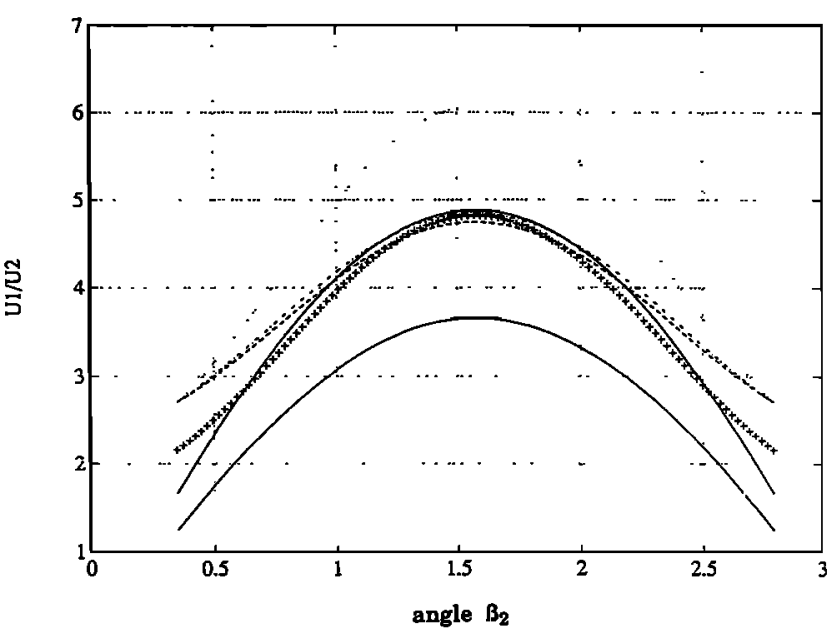

Fig. 12. The two expressions for the wind speed ratio plotted versus variable angle $\beta_{2}$ for a radar cross-section change, $\Delta \sigma=6.5$ $\mathrm{dB}, \beta_{1}=20^{\circ}$, and the following sets of coefficients; $b, c=0.065$, 0.45 (dashed-dotted); $0.20,0.30$ (dotted); and $0.12,0.30$ (dashed). In comparison the curve for $\Delta \sigma=5 \mathrm{~dB}$ and $b, c=0.065,0.45$ (crosses) is shown.

$\Delta \sigma^{0}=6.5 \mathrm{~dB}$ and the angle $\beta_{1}=20^{\circ}$ in the high-wind region. Only the upwind-downwind coefficient value $(b)$ is varied for the latter two pairs, and the corresponding curves are almost identical. The impact of a change in the magnitude of the backscatter is shown with the curve representing the coefficient pair $(0.065,0.45)$, and $\beta_{1}=20^{\circ}$ at $\Delta \sigma=5.0 \mathrm{~dB}$ is plotted for comparison. The curves clearly display possible variations in wind speed ratio across the front for different wind direction geometries in the low-wind region. The ratio is seen to vary by a factor of more than 2. Maximum ratio is always found for $\beta_{2}$ of about $90^{\circ}$. This implies that for a given backscatter change, the corresponding wind speed change across the front would be greatest when the wind direction across the front veers to align with the radar line of sight (i.e., $\Phi_{2}=90^{\circ}$ ) with the low wind region.

In order to look for matching solutions two curves representing the kinematic boundary condition are plotted with the value of $d$ of 1.25 and 1.67 respectively. The curves representing the coefficient pair $(0.20,0.30)$ and $(0.12,0.30)$ are crossed when $d=1.67$, i.e., when the horizontal wind speed normal to the front in the high-wind region is reduced to $60 \%$. At a $6.5-\mathrm{dB}$ backscatter change, the curves cross at an angle of about $57^{\circ}$. When the wind speed ratio is calculated for this angle, we obtain a value of approximately 4 . This is in good agreement with the observed increase in the wind speed from 3 to $11 \mathrm{~m} \mathrm{~s}^{-1}$ across the front. If the backscatter change across the front is reduced to $5 \mathrm{~dB}$, matching solutions are now found for an angle of about $34^{\circ}$. However, in this case the wind speed ratio is too low to agree satisfactorily with the observed. In contrast, no crossing curves are obtained for coefficient combination $(0.065$, $0.45)$ and $\Delta \sigma=6.5 \mathrm{~dB}$ which yields the highest wind speed ratio. Nor is the curve representing $d=1.25$ able to cross the other curves. This may reflect (1) uncertainties in the value of $d$, (2) incorrect estimates of the coefficient pair ( $b$, $c$ ) in the radar scattering equations (5) and (6), and (3) other environmental quantities contributing to the backscatter enhancement across the front.

The method to predict wind speed changes across frontal 
boundaries was further applied to the SAR image expression obtained on March 20 [Mognard et al., this issue]. The steplike frontal boundary in that case reached $8 \mathrm{~dB}$ aligned mainly in the radar line of sight (range) direction, while the wind direction in the high-wind-speed region was about $10^{\circ}$ from range direction. Plotting the two expressions for the wind speed ratio gave matching solutions for a wind direction in the low-wind region of about $135^{\circ}$ relative to the radar range direction. In turn, the estimated ratio (low wind to high wind) yields a value of 0.4 . In comparison, Mognard et al. [this issue] estimated a similar change in wind speed across the front by an iterative solution to the radar cross-section change, taking into account reported wind data from a nearby drilling platform. No direct ship observations were available to validate this result. However, the weather map indicates a gradual change in the wind from southwesterly $10-12 \mathrm{~m} \mathrm{~s}^{-1}$ to northwesterly $2-4 \mathrm{~m} \mathrm{~s}^{-1}$, providing a maximum ratio of 0.4 . This method to obtain quantitative estimates of the mesoscale wind field in vicinity of atmospheric frontal boundaries using the measured radar crosssection change and the kinematic boundary condition across the front is promising but needs further validation.

\section{SUMMARY}

Airborne $\mathrm{C}$ band SAR measurements, ship scatterometer measurements, and in situ observations of meteorological and oceanographic features obtained under unstable stratification in the atmospheric boundary layer during NORCSEX ' 88 have yielded the following revelations.

1. Wind and current modulated frontal structures can be distinguished in SAR imagery.

2. The backscatter modulation induced by wave-current interaction is expressed as a narrow, bright, curving signature associated with a 2-dB peak in the backscatter under certain SAR imaging geometries. In this case the signature was associated with a current jet of $0.3 \mathrm{~m} \mathrm{~s}^{-1}$ opposing the wind direction at an angle of $45^{\circ}$. The feature was associated with a mesoscale upper ocean cyclonic rotating eddy having a shear of $0.3 \times 10^{-3} \mathrm{~s}^{-1}$ and a convergence an order of magnitude less. When this signature is simulated in a Bragg backscatter model using a wind speed of $3 \mathrm{~m} \mathrm{~s}^{-1}$, the Bragg waves remain in equilibrium with the wind, since the relaxation rate is sufficient large to restore the spectrum. We propose therefore to ascribe a major contribution to the backscatter peak from waves of about 0.5-1 $\mathrm{m}$ where the effect of the relaxation rate is smaller. Moreover, we hypothesize that the current gradients may be larger than those inferred from the ADCP measurements. The modulations induced by these upper ocean features are sensitive to the wind speed (relaxation rate) and can be entirely masked at winds exceeding $8-10 \mathrm{~m} \mathrm{~s}^{-1}$.

3. Additional backscatter modulations of $0.65 \mathrm{~dB}$ can be induced by the stress enhancement associated with low winds of $2-3 \mathrm{~m} \mathrm{~s}^{-1}$ opposing the current jet at an angle of $45^{\circ}$.

4. The SAR images manifest the surface roughness change due to wind shift as a steplike transition zone from low to high backscatter intensity induced by the change in wind speed and direction. For a given change in wind direction the wind speed ratio increases exponentially with the magnitude of the backscatter change across steplike fronts. At a given backscatter change on the other hand, maximum wind speed increase is always found when the wind direction turns antiparallel (parallel) to the radar lineof-sight direction in the region of low wind speed. Provided that the kinematic boundary condition is valid and that the wind direction at one side of the front can be estimated from streak patterns or two-dimensional wave spectra, the wind speed change across the front can be directly determined as long as the backscatter intensity is not saturated. Identification of rapid wind shifts and the prediction of the magnitude of wind changes, for example, those associated with polar lows during wintertime, are important for any operation at sea. Spaceborne scatterometers dedicated to surface wind field determination at spatial resolutions from 25 to $50 \mathrm{~km}$ are not capable of detecting these rapid wind shifts. Identification of such wind fronts by the SAR can furthermore resolve the $180^{\circ}$ ambiguity in the wave spectral estimates.

These results are promising for improved utilization of SAR images of the ocean surface. After launch of ERS 1 it is necessary to validate the usefulness of this analysis scheme by coordinated in situ observational campaigns. In particular, the data take should seek to find the maximum current gradients. The goal is to reach a preoperational level for systematic application of ERS 1 SAR imaging data in ocean monitoring and prediction system before the culmination of the ERS 1 duty cycle.

Acknowledgments. We are grateful to Cliff Rufenach, Klaus Hasselmann, and Chuck Livingstone for discussions and suggestions for parts of this study. We also thank Brian Farrelly for his comments. The NORCSEX' 88 program was supported by research councils, institutes and universities of the participating countries. Core support for this study was provided by Royal Norwegian Council for Scientific and Industrial Research (NTNF)/Norwegian Space Center (NSC) under the contract "Norwegian ERS-1 Application Project," Geophysical Institute, University of Bergen, Statoil, European Space Agency (ESA) under a SAR Feasibility Study contract, and Office of Naval Research, U.S.A. The Operation Committee North, consisting of oil companies operating on the Norwegian continental shelf north of $62^{\circ} \mathrm{N}$, financially supported the collection of the SAR data.

\section{REFERENCES}

Barnett, T. P., F. Kelly, and B. Holt, Estimation of the twodimensional ocean current shear field with a synthetic aperture radar, J. Geophys. Res., 94, 16,087-16,097, 1989.

Beal, R. C., P. S. DeLeonibus, and I. Katz (Eds.), Spaceborne Synthetic Aperture Radar for Oceanography, 216 pp., Johns Hopkins University Press, Baltimore, Md., 1981.

Eliassen, A., and K. Pedersen, Meteorology: An Introduction Course, pp. 100-112, University Press, Oslo, Norway, 1977.

Feindt, F., V. Wismann, W. Alpers, and W. C. Keller, Airborne measurements of the ocean radar cross section at $5.3 \mathrm{GHz}$ as a function of wind speed, Radio Sci., 2I, 845-856, 1986.

Fu, L. L., and B. Holt, Seasat views oceans and sea with synthetic aperture radar, JPL Publ. 81-120, 200 pp., Jet Propul. Lab., Pasadena, Calif., 1982.

Gerling, T. W., Structure of the surface wind field from the Seasat SAR, J. Geophys. Res., 91, 2308-2320, 1986.

Haltiner, G. J., and F. L. Martin, Dynamical and Physical Meteorology, 470 pp. McGraw-Hill, New York, 1957.

Hasselmann, K., et al., Theory of synthetic aperture radar ocean imaging: A MARSEN view, J. Geophys. Res., 90, 4659-4686, 1985.

Haugan, P. M., G. Evensen, J. A. Johannessen, O. M. Johannessen, and L. H. Pettersson, Modeled and observed mesoscale circulation during the 1988 Norwegian Continental Shelf Experiment, $J$. Geophys. Res., this issue.

Hughes, B. A., and R. F. Gasparovic, Introduction (Georgia Strait 
and SAR Internal Wave Signature Experiments), J. Geophys. Res., 93, 12,217, 1988.

Johannessen, J. A., The Norwegian Continental Shelf Experiment prelaunch ERS 1 investigation, J. Geophys. Res., this issue.

Jones, L. W., and L. C. Schroeder, Radar backscatter from the ocean: Dependence of the surface friction velocity, Boundary Layer Meteorol., 13, 133-149, 1978.

Kasischke, E. S., D. R. Lyzenga, R. A. Shuchman, and C. C. Wackerman, Contrast ratios of internal waves in synthetic aperture radar imagery: A comparison of SAR Internal Wave Signature Experiment observations with theory, J. Geophys. Res., 93, $12,355-12,369,1988$.

Keller, W. C., V. Wismann, and W. Alpers, The effects of the variations in the sea surface temperature and atmospheric stability in the estimation of the average wind speed by Seasat-SASS, J. Phys. Oceanogr., 14, 392-401, 1989.

Lichy, D. E., M. G. Mattie, and L. J. Mancini, Tracking of warm water ring, in Spaceborne Synthetic Aperture Radar for Oceanography, edited by R. C. Beal, P. DeLeonibus, and I. Katz, pp. 171-182, Johns Hopkins Press, Baltimore, Md., 1981.

Liu, A. K., F. C. Jackson, and E. J. Walsh, A case study of wave-current interaction near an oceanic front, J. Geophys. Res., $94,16,189-16,200,1989$.

Livingstone, C. E., A. L. Gray, R. K. Hawkins, J. G. Halbertsma, R. A. Deane, and R. B. Olsen, CCRS C-band airborne radarSystem description and test results, Proc. Can. Symp. Remote Sens., 11th, 503-518, 1987.

Lyzenga, D. R., and J. R. Bennett, Full-spectrum modeling of synthetic aperture radar internal wave signatures, J. Geophys. Res., 93, 12,345-12,354, 1988.

Mognard, N. M., J. A. Johannessen, C. E. Livingstone, D. Lyzenga, R. Shuchman, and C. Russel, Simultaneous observations of ocean surface winds and waves wind-wave-current interaction by Geosat radar altimeter and airborne synthetic aperture radar during the 1988 Norwegian Continental Shelf Experiment, J. Geophys. Res., this issue.

NORCSEX '88 Group, NORCSEX '88, A pre-launch ERS-1 experiment, Eos Trans. AGU, 70, 1528-1530, 1538-1539, 1989.

Phillips, O. M., The structure of short gravity waves on the ocean surface, in Spaceborne Synthetic Aperture Radar for Oceanography, edited by R. C. Beal, P. S. DeLeonibus, and I. Katz, pp. 24-31, Johns Hopkins University Press, Baltimore, Md., 1981.

Plant, W. J., A relationship between wind stress and wave slope, $J$. Geophys. Res., 87, 1961-1967, 1982.

Rufenach, C. L., R. A. Shuchman, and D. R. Lyzenga, Interpretation of synthetic aperture radar measurements of ocean currents, J. Geophys. Res., 88, 1867-1876, 1983.

Rufenach, C. L., R. A. Shuchman, N. P. Malinas, and J. A Johannessen, Ocean wave spectral distortion in airborne synthetic aperture radar imagery during the Norwegian Continental Shelf Experiment of 1988, J. Geophys. Res., this issue.

Stewart, R. H., Scatter of centimeter waves from the sea, in Methods of Satellite Oceanography, University of California Press, Berkeley, 1985.

Thompson, D. R., B. L. Gotwols, and R. E. Sterner II, A comparison of measured surface wave spectral modulations with predictions from a wave-current interaction model, J. Geophys. Res., $93,12,339-12,343,1988$.

Vesecky, J. F., and R. H. Stewart, The observations of ocean surface phenomena using imagery from the Seasat synthetic aperture radar: An assessment, J. Geophys. Res., 87, 3397-3430, 1982.

Wright, J. W., Detection of ocean waves by microwave radar: The modulation of short gravity-capillary waves, Boundary Layer Meteorol., 13, 87-105, 1978.

K. L. Davidson, Department of Oceanography, Naval Postgraduate School, Monterey, CA 93943.

J. A. Johannessen and O. M. Johannessen, Nansen Environmental and Remote Sensing Center, Edvard Griegsvei 3a, N-5037 Solheimsvik/Bergen, Norway.

D. R. Lyzenga and R. A. Shuchman, Environmental Research Institute of Michigan, P.O. Box 8618, Ann Arbor, MI 48107.

(Received May 2, 1990;

revised September 15, 1990;

accepted August 6, 1990.) 